\title{
Смешанная процедура как международно- правовой механизм регулирования торговых отношений Российской Федерации с Европейскими сообществами и государствами - членами ЕС
}

Муханов A.M.

Правовое регулирование торговых отношений России и Европейского союза осуществляется на основе заключенного в 1994 г. Соглашения о партнерстве и сотрудничестве $(\mathrm{CПC})^{1}$, а также секторальных соглашений ${ }^{2}$. Несмотря на относительное сходство объекта регулирования указанных правовых актов, механизм такого регулирования различается в зависимости от вида соглашения. Эта неоднородность обусловлена различием субъьектного состава СПС и секторальных соглашений. Если в качестве партнера России по СПС наряду с Европейскими сообществами выступают также и их государства-члены, то в секторальных соглашениях параллельное участие государств-членов не допускается.

Вопрос о том, когда Европейское сообщество может самостоятельно заключать международные договоры в области торгово-экономических отношений, а когда государства-члены должны также принимать участие в этом, зависит от объема и характера полномочий наднациональных институтов, которыми они наделены в процессе проведения общей торговой политики ЕС. Так, если компетенция Сообщества является исключительной, то участие государств-членов будет излишним. Если же предмет соглашения выходит за рамки наднациональной компетенции, то государства-члены должны также под-

\footnotetext{
* Муханов Алексей Михайлович - аспирант Центра международно-правовых исследований Института государства и права РАН.

${ }^{1}$ Соглашение о партнерстве и сотрудничестве, учреждающее партнерство и сотрудничество между Российской Федерацией, с одной стороны, и Европейскими сообществами и их государствами-членами, сдругой стороны, от 24 июня 1994 г. // Дипломатический вестник. 1994. № 15/16. С. 29-59.

${ }^{2}$ Agreement between the European Coal and Steel Community and the Government of the Russian Federation on trade in certain steel products// OJ 2002, L 195/55; Agreement between the European Community and the Russian Federation on trade in textile products //OJ 1998, L 169/2, а также ряд других соглашений.
} 
писать соглашение. В этом случае речь идет об использовании так называемой «смешанной процедуры», при которой Сообшество и его государства-члены образуют в отношении партнера по договору (в нашем случае России) одну коллективную сторону - или «группу Сообщества», гарантируюшую имплементацию всех положений смешанного соглашения ${ }^{3}$.

Безусловно, применение «смешанности» вызывает большое количество вопросов как теоретического, так и практического плана. Прежде всего, становится непонятным распределение ответственности и полномочий между сторонами по такому соглашению, т.к. и ЕС, и его государства-члены, заключившие это соглашение, автоматически становятся его полноправными участниками, приобретая соответствующие права и обязанности. Ситуация осложняется еще и тем, что компетенция Сообщества в области общей торговой политики из-за своего динамичного характера вот уже на протяжении десятилетий является предметом острых дискуссий, практически не позволяя партнеру по договору более или менее четко разобраться, на кого в каждом конкретном случае возложены обязательства по исполнению соответствующих положений договора. В рамках настоящей статьи будет предпринята попытка исследовать международно-правовые связи между сторонами, установленные СПС в той его части, которая составляет предмет торговых отношений России с Сообществами и государствами-членами.

\section{Смешанные соглашения: вопросы распределения полномо- чий и ответственности}

\section{1. О понятии «ложная смешанность».}

Применение смешанной процедуры имеет смысл лишь в том случае, если налицо реальный недостаток компетенции ЕС на заключение международных договоров ${ }^{4}$. Иными словами, необходим дефицит компетенции Сообщества в отношении исклочительных и не переданных

\footnotetext{
${ }^{3}$ Neframi E. International Responsibility of the European Community and of the Member State under Mixed Agreements // The European Union as an actor in international relations. The Hague, 2002. P. 193.

${ }^{4}$ CM.: Heliskoski J. Mixed Agreements as a Technique for Organizing the International Relations of the European Community and its Member States. The Hague, 2001 . P. 9.
} 
наднациональным институтам суверснных прав государств - членов $\mathrm{EC}^{5}$. Заключение смешанного соглашения при фактическом отсутствии такого дефицита привело бы к искажению сути смешанной процедуры, усложняя на практике имплементацию смешанного соглаштения и придавая ему таким образом черты «ложной смешанности» ("false mixity") ${ }^{6}$.

В нашем случае использование смешанной процедуры в СПС не является надуманным. Участие государств - членов ЕС обусловлено здесь прежде всего предметом соглашения и соответствующим распределением компетенций межлу наднациональными и межнациональными институтами внутри Европейского Союза. Имеющий место дефицит компетенции Сообщества покрывастся за счет компетенции его государств-членов, поэтому как Сообщество, так и его государствачлены являются необходимыми участниками данного соглашения, гарантируя тем самым его действительность, реализацию и смысл ${ }^{7}$.

\section{2. Разделение компетенций внутри коллективной стороны.}

Разделение компетенции внутри группы Сообщества в смешанном соглашении ставит третье государство-партнера в достаточно щекотливое положение. С одной стороны, возникает вопрос, в каких сферах и в каком объеме происходит такое разделение и в какой мере партнеру группы Сообщества по договору следует учитывать его. С другой стороны, вполне обоснованно опасение государства-партнера в отношении распределения международно-правовой ответственности за нарушение группой Сообщества заключенного соглашения. Остановимся более подробно на первом моменте.

2.1. Компетенция Сообщества на заключение международных договоров.

Договор, учреждающий Европейское сообщество, непредусматривает всеобьемлющей компетенции наднациональных институтов в отно-

${ }^{5}$ Arnold R. Der Abschluss gemischter Vertrдge durch die Europдischen Gemeinschaften // Archiv des Vцlkerrechts. 1980/1981. Band 19. S. 422.

${ }^{6}$ CM.: Rosas A. The European Union and Mixed Agreements // The General Law of E.C. External Relations. London, 2000. P. 200-201.

${ }^{7}$ См.: Лукаиук И.И. Современное право международных договоров. Том I. М., 2004. C. 164-165. 
шении заключения международных договоров. Боле того, компетенция Сообщества ограничена в Договоре отдельными сферами деятельности, что исключает на первый взгляд возможность ее расширения. В то же время анализ практики Суда ЕС показывает, что такого рода ограничения не могут носить окончательного характера. Принципиально важньм здесь является сформулированная Судом AETR-формула ${ }^{8}$, согласно которой Сообщество располагает полномочиями на заключение международных договоров не только в сферах, однозначно переданньх ему учредительными договорами, но также там, где оно уже обладает внугренней компетенцией в соответствии с законодательством ЕС ${ }^{9}$.

Хотя проведенный анализ и подтверждает наличие исключительных полномочий ЕС на заключение международных договоров, как предусмотренных непосредственно учредительными актами Сообщества, так и вытекающих имплицитно из AETR-формулы, данный факт затрагивает в первую очередь правовые последствия в рамках самой группы Сообщества ${ }^{10}$ и не распространяется поначалу на права и обязанности партнера по смешанному соглашению.

Этот вывод, однако, может претерпеть существенные изменения, если проанализировать решение Суда ЕС № 1/78, в соответствии с которым «яв.яется достаточным, когда в отношении партнеров по договору будет установлено наличие разделения предметной компетенции внутри Сообщества, тем не менее точное распределение такой компетенции между Сообществом и его государствами-членами является внутренним вопросом, вмешиваться в который третьи страны неправомочны〉 ${ }^{11}$. Таким образом, Суд не исключает международноправового характера разделения компетенции, а только ограничивает ее детальное распределение рамками Сообщества ${ }^{12}$. В то же время попытка интернационализации разделения компетенции, проведенная одним из органов Сообщества, распространяет свою юридическую силу только внутри группы Сообщества и не может автоматически порождать какие-либо международно-правовые последствия для третьих стран. Поэтому основным вопросом, который должен быть решен

${ }^{8}$ CM.: Case 22/70, Commission v. Council, [1971] ECR 263.

${ }^{9}$ CM.: Eeckhout P. External Relations of the European Union. Oxford, 2004. P. 58-69.

${ }^{10}$ Bernhard R. Die Europдische Gemeinschaft als neuer Rechtstrдger im Geflecht der traditionellen zwischenstaatlichen Rechtsbeziehungen //Europarecht. 1983. S. 205.

${ }^{11}$ Ruling 1/78 [1978] ECR 2151. Para. 35.

${ }^{12}$ Stein K. Der gemischte Vertrag im Recht der АuЯenbeziehungen der Europдischen Wirtschaftsgemeinschaft. Berlin, 1986. S. 78. 
в этой связи, является вопрос признания разделения компетенщии партнером по соглашению.

\section{2. Признание разделения компетенций.}

Содержащаяся в ст. 104 СПС так называемая «разделительная ого-

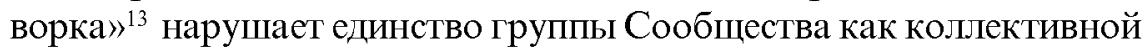
стороны путем проведения различия между Сообществом и его государствами-членами, либо Сообществом и его государствами-членами как компетентными адресатами договорных предписаний. Причем основа такого различия лежит в «их соответствующих полномочиях $)^{14}$. Результатом включения разделительной оговорки в СПС является ситуация, в которой России как стороне Соглашения, для того чтобы найти уполномоченного субъекта внутри группы Сообщества, приходится в той или иной степени иметь дело с нормами права своего партнера по СПС. Уже наличие самой этой ситуации исклочает «безразличие» российской стороны касательно вопроса разделения компетенций внутри группы Сообщества и предполагает ее готовность обеспечить действие такого разделения в отношении себя.

В подтверждение этому необходимо учитывать также то обстоятельство, что вопросы, затрагивагщие торговые отношения России с ЕС, были урегулированы не только с помошњю СПС, но и посредством заключения корреспондируюших секторальных соглашений. Данный факт объясняется тем, что их объектом являются количественные ограничения на поставки некоторых российских товаров в страны ЕС, что в свою очередь составляет объект общей торговой политики Сообщества, осуществление которой находится в исключительной компетенции последнего ${ }^{15}$. Заключив секторальные соглашения, Россия ipso facto признала не только исключительность компетенции Сообщества, касающейся объекта регулирования секторальных соглашений, но также, учитывая предметную взаимосвязь этих секторальных соглашений с СПС, факт разделения компетенции внутри группы Сoобщества.

Подобное признание сопровождается рядом отрицателынх послед-

${ }^{13}$ CM.: Ibid. S. $82-83$.

${ }^{14}$ CT. 104 CП .

15 Этой позиции последовательно придерживается Суд Европейских сообществ, начиная с решения по делу Local Costs. См.: Opinion 1/75, Local Costs Standard, [1975] ECR 1355. 
ствий для российской стороны. Прежде всего это неясность в определении адресата прав и обязательств, Т.к. содержащаяся в СПС разделительная оговорка практически исклочает Россиго из этого процесca, что в свою очередь негативно отражается на предсказуемости правовых отношений, а следовательно, и правовой безопасности российской стороны. С разделительной оговоркой установление такого адресата происходит в соответствии с независимым от воли России разделением полномочий внутри группы Сообщества. Учитывая, что последнее мыслит себя как «развивающуюся систему» ${ }^{16}$ с постоянно менягщимся объемом полномочий, группа Сообщества будет добиваться абсолютизации ее права на определение уполномоченного субъекта обязательства. Иными словами, Сообщество и его государства-члены хотят видеть только себя правомочными решать, на кого из них и в каком объеме ложится обязанность исполнить конкретное предписание СПС, что было бы равносилын выхолащиванию самого правового обязательства ${ }^{17}$.

Стало быть, чтобы гарантировать состояние предсказуемости в созданных СПС правовых отношениях, представляется разумным уточнить, насколько допустима содержащаяся в разделительной оговорке отсылка на «соответствующие полномочия», и вообще, подразумевает ли наличие данного условия изъятие «некомпетентной части» группы Сообщества из-под действия конкретного предписания Соглашения.

Отвечая на первый вопрос, следует обратиться к тексту Конвенции ООН по морскому праву ${ }^{18}$, в которой наряду со своими государствами-членами участие принимает также Европейское сообщество, что делает Конвенцию в этом отношении многосторонним смешанным соглашением. Интерес представляет предложенный там механизм обеспечения предсказуемости при определении адресата обязательств. Приложение XI данной Конвенпии исходит из того, что любое изменение разделения компетенций приобретает только в том случае свою международно-правовую силу, если оно было заблаговременно нотифицировано и, следовательно, признано партнеромпо смешанному соглашениюо ${ }^{19}$.

О необходимости международно-правового признания изменений

\footnotetext{
${ }^{16}$ Heliskoski J. Op. cit. P. 143.

${ }^{17}$ Lauterpacht $H$. Function of Law in the International Community. Oxford, 1933. P. 189.

${ }^{18}$ См.: БМД, № 1, январь 1998 г. Морское право. Организация Объединенных Наций, Нью-Йорк, 1984 г.

${ }^{19}$ См.: ст. 5 Приложения.
} 
в распределении компетенщий как об условии допустимости смены адресата обязательства упоминает также генеральный адвокат Суда ЕС Kanoторти, ограничивая, правда, сферу применения сформулированных им на основе судебной практики принципов международными договорами, заключенными только государствами - членами ЕС ${ }^{20}$. Последнее обстоятельство объясняется тем, что в случае с международными договорами, в которых одной из сторон выступают государства - члены ЕС самостоятельно, изменение в разделении компетенции внутри Сообщества должно повлечь за собой замену стороны договора. Такая смена стала бы для партнеров равнозначной заключениюо нового договора, поэтому признание здесь носит обязательный характер.

Что касается смешанных соглашений, то в этом случае речь идет не о замене стороны всего договора как таковой, а лишь о смене уполномоченного адресата обязательства внутри коллективной стороны, что не дает оснований говорить о возникновении нового договора. Однако при более тщательном рассмотрении правовые последствия для партнера по смешанному соглашению могут быть аналогичными, с тем лишь исключением, что группа Сообщества как сторона соглашения остается, а субъект обязательства постоянно меняется.

В то же время увязывать действительность смены адресата с признанием партнера, если данная возможность не предусмотрена в соглашении, не было бы в полной мере оправданным, т.к. это нарушало бы автономию Сообщества и предполагало бы вмешательство в его внутренние дела $^{21}$. С другой стороны, допустимость замены уполномоченного субъекта посредством механизма признания может представляться обоснованной для гарантирования правовой безопасности партнера и предсказуемости правовых отношений. Признание, правда, в этом случае не может быть конститутивным, если партнер группы Сообщества по смешанному соглашению, действовавший добросовестно, был заблаговременно нотифицирован и если смена адресата обязательства не повлечет нарушение принципа pacta sunt servanda.

2.3. Неделимость юридической силы.

Другим из вышеобозначенных вопросов является распространение юридической силы соглашения на так называемую «некомпетентную часть» группы Сообщества. Следуя логике разделительной оговорки,

${ }^{20}$ Case 812/79, Fischerei: Rechte der Drittldnder, [1980] ECR 2809.

${ }^{21}$ Cм.: Heliskoski J. Op. cit. P. $141-145$. 
некомпетентный адресат не может быть связан нормами соглашения. Однако в доктрине встречаются мнения, которые находят весьма сомнителыным утверждение, что подобного рода оговорка действительно ставит перед собой задачу ограничить юридическую силу отдельных положений соглашения либо Сообществом, либо его государствами-членами ${ }^{22}$. Как доказывает Штайн, это могло бы повлечь весьма негативные последствия как для всей группы Сообщества, так и для партнера последней по смешанному соглашению 23 .

Если бы разделительная оговорка действительно затрагивала юридическую силу каждого отделыного положения соглашения, то неевропейская сторона была бы вынуждена не только абстрактно признать существование факта разделения компетенций как такового, но также обеспечить международно-правовую обязательность конкрегного содержания такого разделения ${ }^{24}$. В свою очередь, это означало бы, что для установления компетентного адресата обязательства в случае отсутствия нотификации или ее неполноты партнеру группы Сообщества пришлось бы самостоятельно искать уполномоченную сторону. Уже сама такая возможность представляла бы непреодолимую проблему для государствапарлнера $^{25}$. Ошибка в определении адресата служила бы основанием для отклонения претензий последнего на исполнение обязательства, что отрицательно сказалось бы на его правовой безопасности. Положение может усугубиться еще более, если рассматриваемое обязательство является предметом спора о компетенции между Сообществом и его государствами-членами. В такой ситуации предсказуемость правовых отношений была бы поставлена под вопрос.

Для Сообщества ограничение юридической силы также имело бы отрицательные последствия. Прежде всего, такое ограничение создавало бы опасность подчинения его правовой системы юрисдикции третьего государства, что было бы несовместимо с тезисом об автономности права Сообщества ${ }^{26}$. Следовательно, сохранение неделимости юридической силы соответствует интересам обеих сторон смешанного соглашения.

${ }^{22}$ CM.: Groux J., Manin P. Die Europдischen Gemeinschaften in der Vцlkerrechtsordnung. Luxemburg, 1984. S. 245.

${ }^{23} \mathrm{Cm}$. Stein K. Op. cit. Kap. 3.

${ }^{24}$ Ibid. S. 97.

${ }^{25}$ Tomuschat C. Liability for Mixed Agreements //O'Keeffe, David und Henry G. Schermers, Mixed Agreements. Deventer, 1983. P. 130.

${ }^{26}$ CM.: Neframi E. Op. cit. P. 204. 


\section{3. Распределение международно-правовой ответственности.}

Наряду с проблемой разделения компетенции в рамках коллективной стороны весьма сложной также является проблема распределения международно-правовой ответственности между ЕС и его государствами-членами. Как и в любом другом смешанном соглашении, не содержащем специальных указаний по этому поводу, партнер группы Сообщества по СПС, отвечая на вопрос, кого считать ответственным за неисполнение отдельного обязательства, будет поставлен перед дилеммой: либо Сообщество и его государства-члены как коллективная сторона несут солидарную ответственность вне зависимости от того, кто является адресатом конкретного обязательства, либо международно-правовая ответственность определяется в соответствии с гранищей разделения полномочий внутригруппы Сообщества ${ }^{27}$.

Поиск однозначного ответа на этот вопрос в нормах Венских конвенций о праве международных договоров (далее Венские конвенции) не в состоянии привести к желаемому результату уже по той причине, что содержащиеся там правила о международно-правовой ответственности, учитывая особую природу смешанной процедуры, не могуг применяться к ней напрямую, а только посредством аналогии ${ }^{28}$. Что касается обычньх норм, то их применение будет ограничиваться, скорее, регулированием общцх вопросов ответственности, присущим всем типам договоров, т.к. фактическое отсутствие практики международно-правовой ответственности Сообщества по вытекающим из смешанньх соглашений обязательствам не позволяет говорить о формировании каких-либо специальных норм международного обычного права в этой области ${ }^{29}$.

В свою очередь, доктрина, несмотря на ее относительную разработанность, также не предоставляет удовлетворяющего все заинтересованные стороны решения данной проблемы. Представленные в ней позиции сводятся в итоге к двум функциональным подходам: международно-правовому подходу, который, пытаясь защитить интересы неевропейской стороны смешанного соглашения, обосновывает солидарную (совместную) ответственность Сообщества и его государств-

${ }^{27}$ Ibid. P. 194.

${ }^{28}$ CM.: Stein K. Op. cit. S. 123-127.

${ }^{29}$ Bjurklund $M$. Responsibility in the EC for Mixed Agreements - Should Non-Member Parties Care? // Nordic Journal of International Law. 2001. P. 376. 
членов, а также ответственность каждого из них в отдельности ${ }^{30}$; и европейскому (коммунитарному) подходу, который, стремясь ограничить применение солидарной ответственности коллективной стороны, исходит из принципа, что ответственность вытекает из соответствующей компетенции (принцип параллельности компетенции и ответственНости) $)^{31}$.

\section{1. Международно-правовой и коммунитарный подходы.}

Чтобы лучшाе понять содержание первого подхода, обратимся к формуле, предложенной генеральным адвокатом Якобсом. Согласно этой формуле, в смешанном соглашении Сообщество и его государства-члены несут солидарную ответственность, если иное не явствует из самого соглашения ${ }^{32}$. Несмотря на кажущуюся очевидность данного утверждения, которое по сути повторяет изложенное выше описание международно-правового подхода, важным здесь является принцип, в соответствии с котором основанием определения ответственности является текст соглашения. То есть Якобс, так же как и Томуuam, ставит во главу угла соображение, что при отсутствии необходимой нотификации о разделении полномочий на партнера группы Сообщества не может быть возложена обязанность «самому наводить справки» об уполномоченной стороне ${ }^{33}$. И хотя впоследствии строгость данной позиции размывается путем навязывания партнеру других источников познания гранищ компстенций, таких как процесс имплементации $^{34}$ или поведение Сообщества в ходе реализации Соглашения $^{35}$, суть изложенной Якобсом формулы остается неизменной: любое основание, исключающее солидарную ответственность группы Сообщества, должно непосредственно вытекать из текста соглашения или

\footnotetext{
${ }^{30}$ Cm.: Stein K. Op. cit. Kap. 5; Tomuschat C. Liability for Mixed Agreements. P. 129.

${ }^{31}$ Cм.: Вjцrklund M. Op. cit. P. 373-402; Pitschas C. Die vцlkerrechtliche Verantwortlichkeit der Europдіschen Gemeinschaft und ihrer Mitgliedsstaaten. Berlin. 2001 . S. 244-245. Отчасти Нефрами..: Neframi E. Op. cit.

${ }^{32}$ Case C-316/91, European Parliament v. Council of the European Union, [1994] ECR I625. Para. 69.

${ }^{33}$ Tomuschat C. Liability for Mixed Agreements. P. 130.

${ }^{34}$ Stein E. External Relations of the European Community; Structure and Process //Collected Courses of the Academy of European Law. Vol. I. Book 1. 1990. P. 162.

${ }^{35}$ Macleod I., Hendry I., Hyett S. The External Relations of the European Communities. Oxford, 1996. P. 162.
} 
следовать из смысла самого обязательства, так чтобы у государствапартнера не возникало никаких сомнений в отношении потенщиального субъекта международно-правовой ответственности.

В глазах сторонников европейского (коммунитарного) подхода такое ограничение источников познания представляется не соответствующим сути смешанной процедуры. По их мнению, наряду с текстом соглашения и практикой имплементации должны быть также привлечены положения учредительного Договора ЕС. Возникающая в результате такого рода интернационализации норм учредительного Договора опасность нарушения автономии Сообщества нейтрализуется посредством предоставления исключительного права на толкование данных норм только Сообществу и его государствам-членам ${ }^{36}$.

\section{2. Сближающий подход.}

Как мы видим, последний подход преимущественно ориентирован на защиту интересов группы Сообщества. Кроме того, предлагаемый способ обеспечения автономии права Сообщества исключает на практике неевропейскую сторону из процесса определения ответственного, оставляя, таким образом, за группой Сообщества окончательное право устанавливать субъекта и степень ответственности, а также содержание и объем обязательства. Поэтому с точки зрения гарантирования предсказуемости правовых отношений и правовой безопасности государства-партнера данный подход не может быть приемлемым.

С другой стороны, распространение солидарной ответственности на группу Сообщества в том виде, как это предлагается сделать авторами международно-правового подхода, не учитывает фактического состояния правовых отношений, вытекаюших из смешанной процедуры. Категорическое отклонение подобного рода ответственности со стороны ЕС и его государств-членов лишаст данный подход всякого практического значения, превращая, с нашей точки зрения, последний в чистую теорию.

В этой связи, не отказываясь в принципе от механизма солидарной ответственности, представляется целесообразным ограничить сферу и объем ее применения. Так, говоря о сфере применения солидарной ответственности, было бы вполне разумным исходить, как это ни странно звучит, из принципа параллельности компетенции и ответственнос${ }^{36}$ Pitschas C. Op. cit. S. 244-245. 
ти ${ }^{37}$. Правда, здесь необходимо отметить, что в случаях, когда индивидуальная ответственность Сообщества или его государств-членов не способна обеспечить надлежащее выполнение обязательств, дополнителыной гарантией для правовой безопасности государства-партнера, как покажет дальнейший анализ, может стать солидарная ответственность группы Сообщества, применяемая в субсидиарном порядке.

Для определения объема солидарной ответственности важную роль играет содержащаяся в смешанном соглашении разделительная оговорка. Одобрив ее, государство-партнер одновременно признало возможность разделения компетенций между Сообществом и его государствами-членами. В то же время предъявленные в адрес Сообщества или его государств-членов претензии партнера в соответствии с принципом неделимости юридической силы должны рассматриваться как претензии, направленные против всей группы Сообщества в целом (солидарная ответственность), в то время как непосредственный адресат ответственности будет определяться коллективной стороной. Последнее обстоятельство исключает предполагаемую солидарной ответственностью индивидуальную ответственность Сообщества за неисполнение обязательств его государствами-членами и, соответственно, такую же ответственность государств ЕС за действия наднационалынгх институтов ${ }^{38}$.

\section{Секторальное применение смешанной процедуры}

\section{1. Содержание торговых отномений.}

Разобрав общее содержание смешанной процедуры, рассмотрим теперь ее конкретное применение в рамках российско-европейских торговых отношений. Для этого необходимо прежде всего определиться с тем, что, собственно говоря, составляет содержание данных отношений.

Если исходить из классического понимания торговых отношений как исключительно торговли товарами ${ }^{39}$, то их предмет мог бы регулироваться третьим разделом СПС. Однако использование такого ограничи-

\footnotetext{
${ }^{37} \operatorname{Rosas}$ A. Op. cit. P. 216.

${ }^{38}$ Neframi E. Op. cit. P. 204.

${ }^{39}$ Monar J. Die Gemeinsame Handelspolitik der Europдischen Union im EUVerfassungsvertrag: Fortschrittemit einigen neuen Fragezeichen // AuЯenwirtschaft. 2005. Heft 1.S. 102
} 
тельного подхода вряд ли отвечало бы современному состоянию мировойторговли, находящейся подвлияниемпроцессов глобализации. Смысл создания ВТО показывает, что только параллелыное регулирование трансграничного предоставления услуг и торговых аспектов интеллектуальной собственности вкупе с торговлей товарами может служить залогом эффективности торговьх отношений. Поэтому для целей настоящего исследования следует брать за основу их широкое понимание.

Последнее обстоятельство обусловливает наличие комплексности международно-правовых связей, вытекающих из применения смешанной процедуры при регулировании российско-европейских ${ }^{40}$ торговых отношений. Предусмотренная в разделе IX Договора об учреждении ЕС общая торговая политика (ОТП), с одной стороны, не наделяет Сообщество исключительной компетенцией в рамках всего спектра торговых отношений, проводимых Россией и ЕС, что делает необходимым задействование национальной компетенции государств - членов Сообщества, а с другой стороны, постоянно изменяет свое содержание в связи с присутствующей динамикой развития наднациональных институтов, что означает неустойчивость правовых связей, порожденных СПС.

Вследствие этого большое значение для правовой безопасности России как партнера группы Сообщества по СПС приобретает состояние развития общей торговой политики ЕС, т.к. именно она является основным фактором при определении адресата обязательства и субъекта ответственности внутри коллективной стороны.

Нужно отметить, что характер и объем общей торговой политики часто варьируются «от продукта к продукту» ${ }^{41}$, а потому при анализе всего спектра торговых отношений представляется логичным рассматривать по отдельности их составляющие: торговлю товарами, трансграничное предоставление услуг и торговые аспекты интеллектуальной собственности.

2. Торговля товарами.

Наиболее предсказуемыми с точки зрения идентификации обязанного и ответственного являтотся правовые отношения вокруг торговли товарами. В этой сфере наднациональные институты наделены ис-

${ }^{40}$ В понимании торговых отношений РФ-ЕС.

${ }^{41}$ Von Bogdandy A. Die Handelspolitik der Europдischen Wirtschaftsgemeinschaft // Jura. 1992. Heft 8. S. 408. 
ключительной компетенцией в отношениипринятия международно-правовых обязательств ${ }^{42}$, а следовательно, они обладают также всей полнотой полномочий по имплементации достигнутых международных договоренностей ${ }^{43}$. Поэтому можно считать, что содержащийся в разделе третьем СПС термин «Стороны» охватывает только наднациональные институты, т.е. Европейское сообщество.

Исключительность компетенции последнего на осуществление торговли товарами, как это уже было описано выше, была признана Россией, в частности путем заключения секторальных соглашений. Кроме того, неоспоримость полномочий Сообщества в отношении торговли товарами вытекает также из факта заключения между Россией и Сообществом Временного Соглашения «О торговле и связанных с торговлей вопросах ${ }^{44}$, по сути, вводившего в действие раздел третий СПС на период до вступления в силу последнего.

Очевидность характера компетенции ЕС и соответствующее признание со стороны России не оставляют сомнений при определении адресата обязательства и субъекта ответственности внутри коллективной стороны-в обоих случаях ими является Европейское сообщество.

В то же время на практике возможны ситуации, когда принцип параллельности компетенции и ответственности не будет действовать. Так, ст. 15 СПС отменяет для российских товаров количественные ограничения, а ст. 19 СПС предусматривает общие исключения из этого правила. Представим себе, что российский экспортер, ввозящий определенный товар на территорию одной из стран ЕС с целыю последующей продажи этого товара на территории другой страны ЕС (государство назначения), сталкивается с введенным государством назначения общим запретом на импорт такого рода товаров на основании ст. 30 Договора об учреждении Европейского сообщества.

Нужно сразу отметить, что примененный запрет не имеет ничего общего с аналогичным запретом ст. 19 СПС, т.к. в рассматриваемом случае его введение находится в исключительной компетенции национальных органов, а не Сообщества и осуществляется на основе права ЕС. Наряду с этим государство назначения, применившее запрет, так-

${ }^{42}$ CM.: Opinion 1/75, Local Costs Standard, [1975] ECR 1355; Opinion 1/94, W TO, [1994] ECR I-5267.

${ }^{43}$ Cm.: Krajew ski M. External Trade Law and the Constitution Treaty: Towards a Federal and More Democratic Common Commercial Policy? // Common Market Law Review 42. 2005. P. 108-109.

${ }^{44}$ CM.: OJ 1995, L 247/2. 
же не вправе обосновывать свое поведение ст. 19 СПС, потому что данная норма носит международно-правовой характер и составляет исключительную компетенцию Сообщества, что уже было признано российской стороной.

В результате, если при разрешении описанной ситуации исходить из принципа параллельности компетенции и ответственности, то на восстановление нарушенных прав российской стороны, предусмотренных ст. 15 СПС, не приходится надеяться. Возможность международноправовой ответственности Сообщества будет отклонена последним на том основании, что запрет, введенный националыными органами власти, не относится к предмету СПС, а следовательно, не затрагивает взаимные права и обязанности сторон по Соглашению. В свою очередь, возложить такую ответственность на государство назначения также не представляется возможным по той причине, что российская сторона признала исключительность полномочий Сообщества в данном вопросе, в то время как рассматриваемый запрет базируется на национальной компетенции государств - членов ЕС, которые в этом случае не будут компетентными адресатами обязательств, вытекающих из ст. 15 СПС. Таким образом, российская сторона оказывается в положении, когда применение механизма международно-правовой ответственности в целях защиты ее прав и интересов будет находиться в противоречии с признанным ею распределением полномочий внутри группы Сообщества.

Решение данной проблемы необходимо искать в самой сути смешанной процедуры, которая призвана обеспечить действие ст. 15СПС в отношении всей коллективной стороныСоглашения внезависимостиот компетентного адресата обязательства (принии неделимости юридической силы) и тем самым гарантировать ответственность либо группы Сооб̆цества в целом, либо ее «уполномоченньх частей»). Признание Россией исключительности компетенции ЕС еще само по себе не означает абсолютизации принципа параллельности компетенции и ответственности. Какпоказал вьшеприведенный пример, наличие исключительной компетенции Сообщества не смогло оградить исполнение международноправового обязательства от влияния национальной компетенции, вследствие чего ограничение международно-правовой ответственности Сообщества за невьполнение обязательств, находяшихся в его исключительной компетенции, только действиями самого Сообщества позволило бы всей коллективной стороне избежать такой ответственности. 
Чтобы этого не произошло, представляется необходимым отойти от строгого применения принципа параллельности компетенции и ответственности и ввести солидарную ответственность ЕС и его государств-членов как коллективной стороны СПС. Более того, в связи с признанием Россией исключительности компетенции Сообщества в отношении ст. 15 СПС солидарная ответственность группы Сообщества будет также означать индивидуальную ответственность наднациональных институтов за действия, совершенные государствами членами ЕC.

\section{3. Трансграничное предоставление услуг.}

В отличие от торговли товарами, такая сфера сотрудничества, как транснациональное предоставление услуг, предполагает задейсгвование националыной компетенци при заключении и имплементации международньх договоров. Объем и сфера подобного правового вмешательства государств - членов ЕС часто являлись предметом институциональньх споров о компетенции между наднациональными и национальными уровнями ЕС и изменялись в зависимости от актуальной редакции Договора об учреждении Европейского сообщества.

На момент заклочения СПС в 1994 г. вопросы трансграничного предоставления услуг рассматривались Судом ЕС во взаимосвязи с предстояाцим учреждением ВТО и параллельным участием в этой организации Сообщества и его государств-членов ${ }^{45}$. В своем решении № 1/94 Суд установил, что входящие в предмет регулирования ГАТС сферы деятельности образуют исключительную компетенцию ЕС только в отношении тех услуг, способ оказания которьх не связан с пересечением границцоставциками или потребителями этих услуг. По мнению Суда, предоставление подобного рода услуг можно было сравнить с торговлей товарами, вследствие чего они подлежали включению в ОТП ${ }^{46}$.

Несравнимыми с торговлей товарами, а следовательно, и не составлявшими содержание общей торговой политики являлись три других перечисленных в ст. 1 ГАТС способа поставки услуг: так называемые «потребление за рубежом», (коммерческое присутствие) и «перемещение физических лиц» ${ }^{47}$. Кроме того, не образовывали и не образу-

${ }^{45}$ CM.: Opinion 1/94, W TO, [1994] ECR I-5267.

${ }^{46}$ Ibid. Para. 44.

${ }^{47}$ См.: Данильчев А.В. Основы торговой политики и правила ВТО. М., 2005. С. 228. 
ют по сей день предмет общей торговой политики также все услуги в сфере транспорта ${ }^{48}$. Таким образом, в отношении этих услуг компетенция Сообщества не являлась исключительной, а была разделена между наднационалыными и национальными уровнями ${ }^{49}$.

С этих же позиций исходила и вступившая в 1999 г. в силу Амстердамская редакция учредительного Договора, которая, по сути, дублировала решение № 1/94, а предусмотренная там возможность распространения общей торговой политики на все сферы трансграничного оказания услуг так и не была использована ${ }^{50}$.

Поэтому, начиная с момента вступления в силу СПС в 1997 г. и заканчивая вступлением в силу Ниццской редакции Договора, учреждающего Европейское сообщество, в 2003 г., созданные СПС правовые связи касательно трансграничного предоставления услуг носили комплексный характер, включая как отношения между российской стороной и группой Сообщества в качестве компетентного адресата обязательства, так и отношения первой с «компетентными частями» коллективной стороны Соглашения.

Другой особенностью этих отношений было отсутствие какого-либо указания на признание Россией природы разделения компетенции внугри группы Сообщества. Что же касается определения адресата обязательства, то оно осуществлялось на основе разделительной оговорки, т.к. ни текст СПС, ни сопутствующие ему секторальные соглашения, ни практика исполнения обязательств не могли служить исчерпывающими источниками познания разделения компетенции.

В результате исполнение обязательств принимало динамичный характер, т.е. России приходилось рассчитывать на возможную смену адресата обязательства, по крайней мере в тех областях поставки трансграничных услуг, которые не были отнесены Судом ЕС к исключительной компетенции наднациональных институтов. Вытекающие отсюда вопросы международно-правовой ответственности должны были решаться на основе принципа неделимости юридической силы, согласно которому Россия обладала правом настаивать на солидарной ответственности коллективной стороны.

Никаких существенных изменений не произошло и со вступлением

${ }^{48}$ Krenzler H. G., da Fonseca-Wollheim H. Op. cit. S. 227.

${ }^{49}$ Opinion 1/94, WTO. Op. cit. Paras. 98 and 105.

${ }^{50}$ Krajewski $M$. External Trade Law and theConstitution Treaty: Towards a Federal and More Democratic Common Commercial Policy?//Common Market Law Review 42. 2005. P. 96. 
в силу в феврале 2003 г. Нищцской редакции учредительного Договора. С одной стороны, его обновленная ст. 133, определяющая предмет и содержание ОТП, отнесла к сфере своего регулирования три последних способа оказания трансграничных услуг ${ }^{51}$. С другой стороны, разрешая государствам - членам ЕС, сохранять ранее заключенные международные договоры в данной области, она оставила открытым вопрос о том, распространяется ли предусмотренная ею исключительность полномочий Сообщества только на принятие соответствующих международноправовых обязательств или же наднационалыные институты обладают также исключителыными правамина их имплементацию.

Представленные по этому поводу в доктрине позиции не отличаются единством мнений и сводятся к двум противоположным подходам. По словам одних авторов, полномочия Сообщества носят исключительный характер как в отношении принятия обязательства, так и в отношении его имплементации ${ }^{52}$. Другие полагают, что подобное сохранение ранее заключенных договоров не станет препятствовать осуществлению лишь внешней компетенции Сообщества ${ }^{53}$, в то время как полномочия на имплементацию принятых международно-правовых обязательств будут разделены между наднациональными и национальными уровнями $\mathrm{EC}^{54}$.

Думается, что позиция, одобрягщая разделение компетенции Сообщества на принятие и имплементацию международно-правовых обязательств, не найдет поддержки у контрагентов ЕС по международным соглашениям. Даже Германн-один из сторонников ограничения компетенции наднациональных институтов - отмечает, что «поскольку Сообщество обладает исключительной компетенцией заключать международные соглашения, то оно должно быть также способшым осуществлять права и выполнять обязанности в отношении своих партнеров $)^{55}$.

Что же касается СПС, то здесь наличие такого разделения вообще не имело бы смысла, т.к. даже если принять, что российская сторона

${ }^{51}$ См.: п. 5 ст. 133 Договора об учреждении Европейского Сообщества.

${ }^{52}$ См.: Krajewski M. Op. cit. P. 96-97; Bourgeois J. The EC's Trade Policy Powers after Nice: Painting Oneself in a Corner? // Mŭlanges en hommage 6 Jean-Victor Louis. Vol. 2. Bruxelles, 2003. P. 32-34.

${ }^{53}$ Hermann C. Common Commercial Policy after Nice: Sisyphus Would Have Done a Better Job //Common Market Law Review. 2002. P. 16.

${ }^{54}$ Krenzler H.G., Pitschas C. Fortschritt oder Stagnation? Die gemeinsame Handelspolitik nach Nizza // Europarecht. 2001. Heft 3. S. 455.

${ }^{55}$ Hermann C. Op. cit. P. 17. 
исходит из исключительности компетенции Сообщества в сфере трансграничного предоставления услуг, то в соответствии с принципом параллельности компетенции и ответственности единственным компетентным адресатом обязательства, а следовательно, и субъектом международно-правовой ответственности в этой ситуации было бы Сообщество. Попьтки же последнего оправдать неисполнение обязательства отсутствием соответствующих полномочий могли бы быть нивелированы применением аналогии ст. 27 Венских Конвенщий, которая в данном случае наряду с предусмотренной смешанной процедурой солидарной ответственностыю коллективной стороны обосновывает индивидуальную ответственность Сообщества за деятельность его государств-членов.

Механизм солидарной ответственности применяется также и в отношении сформулированного в ходе Ницской конференции так называемого «секторального вырезания» ${ }^{56}$, когда поставка культурных, аудиовизуалыных услуг, а также услуг в области здравоохранения, образования и социальной политики исключается из сферы применения общей торговой политики и, таким образом, падаст в совместную компетенцию Сообщества и его государств-членов ${ }^{57}$.

\section{4. Торговые аспекты интеллектуальной собственности.}

Принципиальную схожесть с природой правовых связей, порожденных СПС, в отношении трансграничного предоставления услуг проявляли также урегулированные в ст. 54 Соглашения вопросы торговых аспектов интеллектуальной собственности. Такая идентичность была основана прежде всего на характере компетенции Сообщества, которой оно было наделено в этой сфере. Так же как и в случае с трансграничным оказанием услуг исключительная наднациональная компетенция не распространялась на весь спектр проблем, касающихся торговых аспектов интеллектуальной собственности.

В уже известном нам решении № 1/94 Суд ЕС причислил к общей торговой политике из всего содержания ТРИПС только меры, направленные против свободного хождения контрафактной продукции ${ }^{58}$, т.к. именно они, по мнению Суда, были в наиболышей степени связаны с

\footnotetext{
${ }^{56}$ Krajewski M. Op. cit. Р. 96.

${ }^{57}$ См.: аб. 2 п. 6 ст. 133 Договора об учреждении Европейского Сообщества.

${ }^{58}$ Opinion 1/94, WTO, [1994] ECR I-5267. Para. 55.
} 
регулированием торговли ${ }^{59}$.

Осуществленное таким способом ограничение исключительностикомпетенции Сообщества было в далынейшем признано Россией при заклочении Временного Соглашения «О торговле и связанньх с торговлей вопросах», ст. 18 которого отнесла к сфере своего регулирования вопросы «в области прав интеллектуальной собственности, затрагивающих условия торговли». В результате указанные отношения подлежали изьятию из общего режима ст. 54 СПС, применение которой было основано на использовании разделительной оговорки при определении компетентного адресата обязательства. В то же время формулировка, предложенная во Временном Соглашении, оказалась значительно шире того, что могло пониматься Судомпод мерами, направленньми против свободного хождения контрафактной продукции. Поэтому, рассматривая данную нормув качестве обоснования признания Россией исключительности компетенции ЕС, а следовательно, и его индивидуальной ответственности, необходимо также отметить, что последняя не исключала солидарной ответственности коллективной стороны в случае недостижения согласия по поводу понимания ст. 18 Временного Соглашения.

Относительная определенность в ее интерпретацию была внесена Ниццской редакцией учредительного Договора, ст. 133 которого причислила к содержанию ОТП «торговые аспекты» прав интеллектуальной собственности. И хотя их точная дефиниция не была предусмотрена, логика ниццских изменений состояла в расширении границ ОТП за счет включения в нее всех областей деятельности, составляющих предмет ТРИПС ${ }^{60}$. Данное обстоятельство закладывает, в свою очередь, границы понимания ст. 18 Временного Соглашения, а значит и сферы индивидуалынй ответственности наднационалыных институтов в рамках ст. 54 СПС. Иначе говоря, российская сторона, признав посредством заключения Временного Соглашения исключительность полномочий Сообщества, должна также рассматривать последнее в качестве компетентного адресата обязательств, предмет которых идентичен с областью регулирования ТРИПС.

$* * *$

Использование смешанной процедуры в российско-европейских тор-

${ }^{59}$ Ibid. Para. 63.

${ }^{60} \mathrm{CM} .:$ Hermann C. Op. cit. P. 17-18. 
говых отношениях носит сложный, а порой и запутанный характер. Не зря немецкий профессор Томуиат призывает избегать смешанности там, где это возможно ${ }^{61}$. Основная роль в установлении границ ответственности и разделения компетенции в рамках коллективной стороны принадлежит степени «наднационализации» материй, составляющих предмет общей торговой политики ЕС. Там, где правовое регулирование полностью отдано на откуп наднациональным институтам, возникает исключительная компетенция последних на принятие и имплементацию международно-правовых обязательств. Если данный факт нашел впоследствии свое международно-правовое признание, то в такой ситуации оправданно применение принципа параллельности компетенции и ответственности.

Состояние общей торговой политики не исключает также случаи, когда исключительная компетенция Сообщества распространяется только на принятие обязательства, передавая его исполнение в область конкурирующей компетенпииилинационалынойкомпетенции государств - членов ЕС. В результате для того, чтобы гарантировать правовую безопасность российской стороны, недостаток компетенции Сообщества будет компенсироваться использованием механизма солидарной ответственности колшективной стороны и индивидуальной ответственности Сообщества за деятельность его государств-членов.

Еще одним вариантом является принадлежность обязательства к конкурирующей компетенции. Здесь вопросы международно-правовой ответственности группы Сообщества будут решаться посредством применения разделительной оговорки, предусмотренной в ст. 104СПС, а также принципа неделимости юридической силы. Вытекающим отсюда последствием станет солидарная ответственность коллективной стороны Соглашения.

${ }^{61}$ CM.: Tomuschat C. Vulkerrechtliche Grundlagen der Drittlandsbeziehungen der EG. S. 146. 